Phytochemistry 130 (2016) 313-320

http://dx.doi.org/10.1016/j.phytochem.2016.07.002

\title{
Structural Characterization of Allomelanin from Black Oat
}

\author{
Mónika Varga ${ }^{\mathrm{a}, \mathrm{b}^{*}}$, Ottó Berkesi ${ }^{\mathrm{c}}$, Zsuzsanna Darula ${ }^{\mathrm{d}}$, Nóra Veronika May and András \\ Palágyi ${ }^{\mathrm{b}}$
}

\begin{abstract}
${ }^{a}$ National Agricultural Research and Innovation Centre, Research Department of Field Crops, H-6726 Szeged, Alsókikötő sor 9, Hungary

${ }^{\mathrm{b} C e r e a l ~ R e s e a r c h ~ N o n-P r o f i t ~ L t d ., ~ H-6726 ~ S z e g e d, ~ A l s o ́ k i k o ̈ t o ̋ ~ s o r ~ 9, ~ H u n g a r y ~}$

${ }^{\mathrm{c}}$ Department of Physical Chemistry and Materials Science, University of Szeged, Aradi Vt. 1., H-6720 Szeged, Hungary

${ }^{\mathrm{d}}$ Laboratory of Proteomics Research, Institute of Biochemistry, Biological Research Centre of the Hungarian Academy of Sciences, H-6726 Szeged, Temesvari krt 62, Hungary

${ }^{\mathrm{e}}$ Institute of Organic Chemistry, Research Centre for Natural Sciences, Hungarian Academy

of Sciences, Magyar tud osok k€orútja 2, H-1117, Budapest,

Hungary
\end{abstract}

\begin{abstract}
The brown to black coloration found in plants is due to the melanins, which have been relatively poorly investigated among the plant pigments. The aim of this work was to study the dark pigment extracted from the black oat hull with respect to composition and structure. Ultraviolet-visible (UV-Vis) spectroscopy, electron paramagnetic resonance (EPR) spectroscopy, matrix-assisted laser desorption/ionization-time of flight mass spectrometry (MALDI-TOF MS) and Fourier transform infrared (FT-IR) spectroscopy were applied for the characterization of the pigment. UV-Vis spectroscopy revealed that the extracted material displayed the absorption profile typical of melanins. MALDI-TOF MS measurements demonstrated that oat melanin is a homopolymer built up from $p$-coumaric acid and consists mainly of low molecular weight (500-900 Da) oligomers of between 3 and 9 monomer units. The tetramer oligomer proved to be dominant. The results of the FT-IR analysis indicated that oat melanin is a fully conjugated aromatic system containing tetrasubstituted aromatic rings linked by $\mathrm{C}-\mathrm{C}$ coupling. The in vitro preparation of melanin from $p$-coumaric acid by horseradish peroxidase was performed for comparison. The resulting polymer consisted of oligomers of 4 to 9 monomer units similarly to those in oat melanin. However the building blocks proved to be connected to each other via $\mathrm{C}-\mathrm{O}-\mathrm{C}$ linkages in contrast with the $\mathrm{C}-\mathrm{C}$ linkages in oat melanin. This is the first demonstration of the structure of melanin originating from plants.
\end{abstract}

Keywords: melanin, oat, $p$-coumaric acid, MALDI-TOF MS, FT-IR spectroscopy

\section{Introduction}

Among the plant pigments the chemistry, biochemistry and biosynthetic pathways of the flavonoids responsible for the pale-yellow to blue coloration and the yellow to red carotenoids and betalains have been thoroughly investigated (Tanaka et al., 2008; Grotewold, 2006). In contrast the origin and nature of the black coloration in plants have been poorly studied (Nicolaus, 1968).

The brown to black pigments found in animals, microorganisms and plants are melanins, pigments that are not essential for development, but rather have a defensive role in all 
organisms. In man and other vertebrates, melanins function in camouflage (Morison, 1985) and photoprotection (Ortonne, 2002). Melanins protect fungi against microbial and environmental stresses such as UV irradiation or desiccation. (Bell and Wheeler, 1986). In the plant kingdom, the intensity of melanin formation is often correlated with resistance to microbial and viral infections and unfavorable climatic conditions (Bell, 1981). The response of plants to bruising or cutting likewise includes the production of melanins (Marshall et al., 2000).

Melanins are biopolymers formed from phenolic compounds by polymerization via quinones. The production of quinones is catalysed by the phenoloxidases.

Melanins can be classified on the basis of their precursor molecule. In animals, the black eumelanins and the reddish-brown pheomelanins are derived from tyrosine. Melanins in fungi and other microorganisms are derived from tyrosine via 3,4-dihydroxyphenylalanine (DOPA), $\gamma$-glutaminyl-3,4-dihydroxybenzene (GDHB) or catechol, and 1,8-dihydroxynaphthalene (DHN) (Bell and Wheeler, 1986). It is believed that the precursor in plants is catechol, caffeic, chlorogenic, protocatechuic, or gallic acid (Solano, 2014), but there is not yet evidence.

The structures of melanins have rarely been studied due to the difficulties in the isolation of melanins from natural sources and the poor solubility of the pigments. Melanins are insoluble in water and common organic solvents (such as hexane, chloroform, ethyl acetate, ethanol, methanol or acetone) (Sava et al., 2001a; Hsieh and Lien, 2012; Wang et al., 2006) and can be dissolved only in alkaline solutions. The range of available structural investigation methods is therefore limited. Knowledge of the structure has been derived largely from chemical degradation studies and the analysis of pigments synthetized in vitro from the presumed precursor monomers. (Napolitano et al., 1996a, 1996b). To date, detailed accounts of the structural elucidation of melanins have been reported only in the case of the nitrogen-fixing bacteria Azotobacter chroococcum (Banerjee et al., 2014) and Sepia officinalis (Pezzella et al., 1997). Both pigments proved to be eumelanins built up from 5,6-dihydroxyindole and/or 5,6-dihydroxyindole-2-carboxylic acid monomer units. Analytical methods have been established for the quantitative determination of eumelanins and pheomelanins, in view of their important role in skin and hair pigmentation. The methods are based on oxidative degradation of the biological samples followed by high performance liquid chromatographic quantification of specific degradation products (Ito and Fujita, 1985; Napolitano et al., 2000). Despite their frequent occurence, plant melanins have been poorly investigated, generally in studies limited to their isolation and characterization of their physical and chemical properties (e.g. solubility, stability and oxidized bleaching) (Claussen and Pepper, 1968; Sava et al., 2001a). Little structural information is available, namely the pigment is devoid of nitrogen and the $\mathrm{C} / \mathrm{H}$ ratio of 1.11 indicating an aromatic nature.

Oat is a cereal crop primarily used as animal fodder, but an increasing amount is now being grown for human consumption, following the recent recognition of its nutritional benefits. There are several oat subspecies. Avena sativa and Avena byzantina are the most commonly cultivated in the world. The oat grain is comprised of the hull and kernel (groat). The whole oat usually consists of $25-35 \%$ hull, depending on environmental and genetic factors, but there are naked oat cultivars too (Coffman, 1961). The hull varies in color in the different varieties, the most common colors being white, yellow, reddish-brown and black. The hull mainly consists of hemicelluloses, cellulose and lignin (Rasper, 1979). It also contains proteins (Welch el al., 1983) and phenolic compounds in low quantities (Chen et al., 1982). No data are available as concerns the pigments present in the hull.

The objective of the present study was to characterize the dark pigment extracted from the black oat hull with respect to its composition and structure. The analytical techniques applied for the characterization of the pigment included ultraviolet-visible (UV-Vis) spectroscopy, electron paramagnetic resonance (EPR) spectroscopy, matrix-assisted laser 
desorption/ionization-time of flight mass spectrometry (MALDI-TOF MS) and Fourier transform infrared (FT-IR) spectroscopy. The biopolymer synthetized in vitro from the presumed precursor monomer by peroxidase-initiated polymerization was studied for comparison.

This is the first report related to the structural characterization of melanin originating from plants.

\section{Results and Discussion}

\subsection{Characterization of the dark pigment obtained from oat hull}

The black pigment of the oat hull was isolated from the plant matrix by alkaline extraction. Purification was performed according to Sava et al. (2001b). The multistep process started with acid hydrolysis to remove carbohydrates and proteins, which was followed by washing with organic solvents to remove lipids. The final step was a repeated precipitation to eliminate phenolic compounds. As a result of the extraction and purification $5 \mathrm{mg}$ pigment was obtained from $1 \mathrm{~g}$ oat hull.

\subsubsection{UV-Vis and EPR spectroscopy}

$\mathrm{UV}$-Vis spectroscopy and electron paramagnetic resonance spectroscopy were applied to identify obtained melanin.

The UV-Vis spectrum of the extracted and purified pigment is shown in Suppl. Fig. S1. The absorbance increases progressively towards shorter wavelengths and there is strong absorption around $200 \mathrm{~nm}$. This broadband, structureless absorption profile monotonously increasing function of energy is typical of the melanins (Crippa et al., 1978).

Melanins can be identified as paramagnetic biopolymers due to the presence of stable free radicals. Free radicals can be easily observed by electron paramagnetic resonance spectroscopy. The EPR signal (Fig. 2) of the dark pigment extracted from oat hull appears as a singlet, without any fine structure similarly to the EPR spectra of other synthetic and natural melanins from different origin (Mason et al., 1960; El-Obeid et al., 2006). The g value of the signal was calculated to be 2.0051 typical to carbon-centred organic free radicals on a conjugated structure with oxygen containing functional groups (Atherton et al., 1993).

\subsubsection{MALDI-TOF mass spectrometry}

MALDI-TOF MS is a powerful method to obtain structural information on the polymers such as the degree of polymerization, and the molecular masses of the repeating units, and the oligomers (Nielen, 1999).

The MALDI-TOF mass spectrum of oat melanin (Fig. 2) resembles those of synthetic homopolymers. It is characterized by a series of peaks representing oligomers with different degrees of polymerization. The spectrum reflects the oligomers in their potassium adduct form. Because of the high cation affinity of the polymers, their ionization often takes place by cationization (Knochenmuss et al., 1998). The peak-to-peak distance which is the molecular weight of the repeating unit is $162 \mathrm{Da}$. As the monomers are linked to each other, the molecular mass of the monomer can be calculated $(162+2 \mathrm{Da})$. The allomelanins are known to be formed from phenolic compounds by phenoloxidase enzymes. Phenolic acids in plants can be divided into two groups: hydroxylated derivatives of benzoic and cinnamic acids (Fig. 3 ). The hydroxybenzoic acids include $p$-hydroxybenzoic, protocatechuic, gallic, vanillic and syringic acids, which in common have a C6-C1 structure. The hydroxycinnamic acids, on the other hand, contain a three-carbon side-chain (C6-C3), with $p$-coumaric, caffeic, ferulic and sinapic acids being the most common (Balasundram et al., 2006). In view of their structure and the calculated molecular weight of the monomer, it is obvious that the monomer is $p$ - 
coumaric acid. The MALDI experiments demonstrated that oat melanin consists mainly of low molecular weight (500-900 Da) oligomers built up from between 3 and 9 monomer units, the tetramer oligomer is dominant (Fig. 2). Large polymeric structures are not observed. Interestingly, these results are consistent with the findings of the structural investigation of Sepia melanin and synthetic melanins (Napolitano et al., 1996a, 1996b; Pezzella et al., 1997) despite being formed from completely different building blocks. The main difference is that this plant melanin is homogeneous, in contrast with the heterogeneous animal and bacterial melanins.

Our results are novel not only as concerns melanin, but for other reasons too. Among the hydroxycinnamates, only ferulate oligomers (dimers, trimers and tetramers) have already been isolated from plants (maize, wheat and rye) (Bunzel, 2010). They act as cross-links between the cell wall polymers (polysaccharides, proteins and lignin), contributing to the strengthening of the cell wall and the defense mechanisms of the plants against pathogens. No data have been published previously in connection with either $p$-coumarate oligomers or hydroxycinnamate oligomers, in general from pentamers to octamers, obtained from plants.

\subsubsection{FT-IR spectroscopy}

FT-IR spectroscopy is a powerful tool for identification of the characteristic functional groups and their changes as a result of polymerization. Through this, therefore, the structure of the polymer can be predicted. The FT-IR spectra of the presumed precursor monomer ( $p$ coumaric acid) and oat melanin are shown in Fig. 4.

$p$-Coumaric acid is a hydroxycinnamic acid and the IR spectra of the monomer and the polymer should therefore display the characteristic absorption of the phenolic $\mathrm{OH}$, the aromatic ring, and the methylene and carbonyl groups.

\section{Phenolic $\mathrm{OH}$}

The stretching vibration of the phenolic (and carboxylic) $\mathrm{OH}$ group appears in the region $3400-3100 \mathrm{~cm}^{-1}$. The band broadening related to the inter- and intramolecular hydrogen bonding is more pronounced for the melanin sample. In both IR spectra, the strong absorption band observed at $1210 \mathrm{~cm}^{-1}$ originates from the C-O (stretching) deformation of the phenolic hydroxyl group (Kavamura and Higoushi, 1969). In-plane bending modes of the phenolic (and carboxylic) $\mathrm{OH}$ are located at 1423 (Varsányi, 1973) and around $1370 \mathrm{~cm}^{-1}$ in both compounds. Thus, there is a phenolic $\mathrm{OH}$ group in the oat melanin sample, and consequently it does not take part in a $\mathrm{C}-\mathrm{O}-\mathrm{C}$ linkage between the monomer units.

\section{Methylene and the carboxylic groups}

In the IR spectra of $p$-coumaric acid, the absorption band at $1625 \mathrm{~cm}^{-1}$ is caused by the stretching vibration of the $\mathrm{C}=\mathrm{C}$ bond. The out-of-plane $\mathrm{C}-\mathrm{H}$ vibration characteristic of a disubstituted double bond with trans configuration is present at $977 \mathrm{~cm}^{-1}$. Because of peak broadening these absorption bands can not be observed in the oat melanin spectrum. However, the presence of the $\mathrm{C}=\mathrm{C}$ bond in the melanin sample is proved by the position of the $\mathrm{C}=\mathrm{O}$ stretching vibration characteristic of the carboxyl group. When a carboxyl group is conjugated with an olefinic bond, the $\mathrm{C}=\mathrm{O}$ stretching vibration appears at around $1690 \mathrm{~cm}^{-1}$ (Mohan, 2002). This band is located at $1696 \mathrm{~cm}^{-1}$ for the melanin sample, but it is shifted toward lower frequency $\left(1668 \mathrm{~cm}^{-1}\right)$ in the case of the monomer, due to the dimerization via an intermolecular hydrogen-bond. Oat melanin therefore posseses a carboxyl group conjugated with a $\mathrm{C}=\mathrm{C}$ group.

\section{Aromatic ring}

One of the aromatic C-C stretching vibration bands in the IR spectrum of the melanin sample is located at $1591 \mathrm{~cm}^{-1}$ while it is observed as a doublet at 1600 and $1589 \mathrm{~cm}^{-1}$ in the case of the monomer. In substituted benzenes this quadrant stretching (at $1600 \mathrm{~cm}^{-1}$ ) of the $\mathrm{C}-\mathrm{C}$ bond is not sensitive to changes in ortho, meta or para substitution. (Colthup, 1990). However, the 
other C-C stretching band has two components: one at $1510 \mathrm{~cm}^{-1}$, characteristic of phenyls, and the second at around $1446 \mathrm{~cm}^{-1}$ relating to the substitution pattern of the aromatic ring (Mohan, 2002). The first component is located at $1510 \mathrm{~cm}^{-1}$ in both IR spectra. Differences were observed for the second component, indicating differences in the substitution pattern: the absorbance in the melanin appeared at $1462 \mathrm{~cm}^{-1}$ while $p$-coumaric acid exhibits a band at $1446 \mathrm{~cm}^{-1}$.

The IR spectrum of the monomer contains bands at 1170,1103 and $1013 \mathrm{~cm}^{-1}$ due to the vibration of the aromatic in-plane $\mathrm{C}-\mathrm{H}$ bends. The vibration pattern of the melanin sample is completely different in this region: two bands appear at 1157 and $1124 \mathrm{~cm}^{-1}$ and there is a strong band at $1026 \mathrm{~cm}^{-1}$.

The out-of-plane aromatic C-H bend vibrations $\left(900-675 \mathrm{~cm}^{-1}\right)$ can be regarded as structural identifiers. Their intensities and positions are characteristic of the substitution pattern of the aromatic ring. In the IR spectrum of $p$-coumaric acid, there is a sharp band at $827 \mathrm{~cm}^{-1}$ typical of para substitution. The situation is completely different in the case of the melanin sample: there are weak bands at 860 and $844 \mathrm{~cm}^{-1}$ and a medium band at $800 \mathrm{~cm}^{-1}$ indicating to tetrasubstitution of the aromatic ring (Socrates, 2004).

In a study of the peroxidase-catalyzed polymerization of caffeic acid, $\mathrm{Xu}$ et al. (2005) observed two weak bands at 850 and $840 \mathrm{~cm}^{-1}$ and a strong band at $800 \mathrm{~cm}^{-1}$. They attributed these bands to the out-of-plane deformation vibration of two isolated $\mathrm{H}$ atoms, which corresponds to tetrasubstitution of the aromatic ring.

We can conclude that absorption bands characteristic of the carboxylic and phenolic $\mathrm{OH}$ groups and the olefinic bond can be identified in the IR spectrum of oat melanin. Only the vibration bands characteristic of the aromatic ring are changed relative to those in the spectrum of the monomer. It follows that oat melanin involves an aromatic system containing tetrasubstituted aromatic rings. With regard to the possible resonance structures of the radical (Fig. 5) the melanin polymer may be formed by the radical coupling of the II. intermediate. Consequently, we may surmise the following structure of oat melanin (Fig. 6).

\subsection{Characterization of the enzymatic polymerization of $p$-coumaric acid}

The plant melanins are formed from phenolic acids by oxidative polymerization catalyzed by polyphenol oxidases. Our results suggest that the monomer of oat melanin is $p$-coumaric acid and we therefore attempted the in vitro enzymatic synthesis of melanin from $p$-coumaric acid. From practical considerations peroxidase was used instead of polyphenol oxidase. The difference between peroxidases and polyphenol oxidases is that the former require hydrogen peroxide as oxidizing agent, while polyphenol oxidases need oxygen. Peroxidases are generally used as catalysts in the oxidative polymerization of aromatic compounds (Reihmann and Ritter, 2006). The enzymatic polymerization was initiated by the dropwise addition of hydrogen peroxide to the mixture of the monomer and the enzyme. Immediately after the addition of the oxidant, the mixture turned black, indicating the formation of quinones, and then changed to orange. The rusty-colored polymer precipitated after continuous stirring for $36 \mathrm{~h}$.

To establish whether melanin was produced from $p$-coumaric acid in vitro, the structure of the product was investigated by UV-Vis, FT-IR spectroscopy and MALDI-TOF MS.

\subsubsection{UV-Vis spectroscopy}

The UV-Vis spectra of $p$-coumaric acid and the polymer are presented in Fig. 7. Four absorption bands overlapping in pairs are characteristic of the monomer, corresponding to the substituted aromatic ring $(210 \mathrm{~nm}$ and $310 \mathrm{~nm})$, the $\mathrm{C}=\mathrm{C}$ bond in the side-chain that is conjugated with the aromatic ring $(290 \mathrm{~nm})$ and the conjugated $\mathrm{C}=\mathrm{O}$ group attached to the ring by a side-chain containing a double bond (224 nm) (Bartolomé et al., 1993). The 
oxidative polymerization leads to changes in the absorption bands corresponding to the aromatic ring, and particularly the band at $210 \mathrm{~nm}$. It seems that the absorption bands of the chromophores in the side-chain $(224 \mathrm{~nm}$ and $290 \mathrm{~nm})$ were not affected by the enzymatic reaction. The monotonously increasing absorption toward higher energies typical of melanins can be observed only in the range 200-240 nm. It may therefore be concluded that the product of the in vitro enzymatic oxidation of $p$-coumaric acid is similar in part to the natural melanin obtained from the oat hull.

\subsubsection{MALDI-TOF measurements}

Fig. 8 depicts the result of the MALDI-TOF MS analysis of the polymer sample prepared in vitro. The overall peak distribution pattern is similar to that observed for the oat melanin sample. However the spectrum displays some high-intensity peaks and a series of lowerintensity peaks in contrast with the peaks with successively decreasing abundance in the spectrum of oat melanin (Fig. 2). Mass differences of $162 \mathrm{Da}$ are observed between the pairs of peaks and the individual peaks at $\mathrm{m} / \mathrm{z} 536$ and 580, $\mathrm{m} / \mathrm{z} 698$ and 742, $\mathrm{m} / \mathrm{z} 860$ and 904, $\mathrm{m} / \mathrm{z}$ 1022 and $m / z$ 1184. These results indicate that oligomers are formed from $p$-coumaric acid on reaction with horseradish peroxidase in vitro. The oligomers were detected as ammonium ion adducts because the sample applied to the MALDI sample target was dissolved in ammonia solution. The group of peaks from $\mathrm{m} / \mathrm{z}, 427$ to $\mathrm{m} / \mathrm{z}, 462$ represent the different adduct ions of the decarboxylated trimer and ions related to the 2,5-Dihydroxybenzoic acid (DHB) matrix. They are enlarged in the inset. The peaks at $\mathrm{m} / \mathrm{z}$ 580, 742 and 904 correspond to the oligomers ( $\mathrm{n}=4,5$ and 6 , where $\mathrm{n}$ is the degree of polymerization) formed by the loss of two carboxyl groups. The lower-intensity peaks at $\mathrm{m} / \mathrm{z}$ 698, 860, 1022 and $1184(\mathrm{n}=5,6,7$ and 8) are assigned to the oligomers, formed by the loss of three carboxyl groups. It has already been demonstrated that decarboxylation is a major factor in the formation of oligomers if the free acids are used instead of the esters during the oxidative/radical coupling of the cinnamates by peroxidase, laccase or $\mathrm{MnO}_{2}$ (Bunzel et al., 2008). Besides the results on oat melanin our findings with the polymer prepared in vitro are also novel. $p$-Coumarate dimers and trimers formed on the use of Momordica charantia peroxidase (Liu et al., 2007), and dehydrotetramers formed on the use of onion peroxidase, (El Agha et al., 2012) have already been described in model systems. Our present study demonstrates for the first time the formation of $p$-coumarate oligomers containing up to 8 monomer units as a result of peroxidase-initiated polymerization of this hydroxycinnamic acid.

\subsubsection{FT-IR spectroscopy}

FT-IR spectroscopy can provide information on possible types of linkages between the $p$ coumaric units in the in vitro prepared polymer.

At first glance, the IR spectrum of the melanin prepared in vitro (Fig. 9) is similar to that of oat melanin, though some differences are observed.

\section{Phenolic $\mathrm{OH}$}

The broad band attributed to the stretching vibration of the $\mathrm{OH}$ group is located in the interval $3600-3000 \mathrm{~cm}^{-1}$ similarly as for the oat melanin sample.

The $\mathrm{C}-\mathrm{O}$ stretching vibration of the phenolic $\mathrm{OH}$ group appears as a slight shoulder of the band at $1224 \mathrm{~cm}^{-1}$ assigned to the antisymmetric C-O stretch of diaryl ethers (there is no other band relating to the $\mathrm{C}-\mathrm{O}$ stretch because the symmetric $\mathrm{C}-\mathrm{O}$ stretching is absent in the case of diaryl ethers) (Dahlgard et al., 1958). The presence of this band suggests that the monomers are linked by C-O-C bonds in the polymer.

Methylene and carboxylic groups

The stretching vibration of the $\mathrm{C}=\mathrm{O}$ bond characteristic of the carbonyl group appears as a doublet at 1687 and $1659 \mathrm{~cm}^{-1}$ in contrast with the broad absorption observed for the oat 
melanin sample. Splitting or broadening of the carbonyl absorption is typical for $\alpha, \beta-$ unsaturated, conjugated systems because they have two rotational isomers possessing s cis and s trans conformations (Vyvyan et al., 2008). However, the evidence for the presence of the $\mathrm{C}=\mathrm{C}$ bond is not only circumstantial. The stretching vibration and the $\mathrm{C}-\mathrm{H}$ out-of-plane bending vibration of the olefin bond can be observed at $1628 \mathrm{~cm}^{-1}$ and $974 \mathrm{~cm}^{-1}$, respectively. The $\mathrm{C}=\mathrm{C}$ bond of $p$-coumaric acid was therefore not changed by the enzymatic polymerization.

\section{Aromatic ring}

Aromatic skeleton vibration bands, which are not influenced by the substitution of the ring are located at $1597 \mathrm{~cm}^{-1}$ and $1504 \mathrm{~cm}^{-1}$ in the IR spectra of oat melanin and $p$-coumaric acid. The second component of the semicircle stretching vibration, which reflects the substitution pattern, appears at $1487 \mathrm{~cm}^{-1}$. This band is characteristic of 1,2,4-trisubstituted aromatics.

Aromatic in-plane C-H bands are found at 1167 and $1119 \mathrm{~cm}^{-1}$. In the spectra of the investigated compounds these bands appeared at different frequencies.

The out-of-plane $\mathrm{C}-\mathrm{H}$ bending vibration bands can indicate the positions of the substituents on the aromatic ring. The bands at 864 and $827 \mathrm{~cm}^{-1}$ can be assigned to the bending vibration of an isolated hydrogen and two adjacent hydrogens, respectively. Similarly to the vibration bands of the aromatic skeleton, these absorption bands confirm, that the aromatic ring is trisubstituted as a result of the polymerization (Socrates, 2001).

The IR spectra suggest that the $p$-coumaric units are ether-linked $(\mathrm{C}-\mathrm{O}-\mathrm{C})$ in the polymer prepared in vitro and the aromatic ring is 1,2,4-trisubstituted. Thus, of the mesomer structures of the radical formed from the monomer by the action of horseradish peroxidase (Fig. 5), $\mathbf{I}$. and II. can be coupled to build up the polymer. The proposed structure is illustrated in Fig. 10 .

The findings that the polymer is composed of oxyphenylene units is consistent with literature results on the enzymatic polymerization of phenolic monomers (Aktas et al., 2003; Ikeda et al., 1998; Marjasvaara et al., 2006). In consequence of the C-O-C coupling, the synthetic polymer can not be regarded as a fully conjugated system. This is the explanation of the strong UV absorption missing around $210 \mathrm{~nm}$.

Our attempts to prepare melanin in vitro in order to compare the structures of the natural and synthetic biopolymers and to prove that oat melanin is built up from $p$-coumaric acid were successful partially. Similarly to oat melanin the synthetic polymer consists of oligomers of 4 to 9 monomer units. However, the building blocks are connected to each other via an ether linkage in the biopolymer prepared in vitro in contrast with the $\mathrm{C}-\mathrm{C}$ linkage found in oat melanin. Similar phenomenon was observed by Liu et al. (2007) during their investigations of the surface-induced enzymatic polymerization of caffeic acid in comparison with the solution polymerization. They concluded that the polymer was formed by $\mathrm{C}-\mathrm{C}$ ring coupling from the monomer previously bonded to the surface, while mainly aromatic ethers were produced as a result of the solution polymerization. This structural difference was attributed to the surface organization and orientation of the monomer. In plants, phenolic acids occur partially in free form, but they are mostly ether-linked to lignin through their $\mathrm{OH}$ groups and ester-linked to structural carbohydrates and proteins through their carboxyl groups (Bunzel, 2010). It may be surmised that the orientation of $p$-coumaric acid by the cell wall polymers contributes to the formation of the $\mathrm{C}-\mathrm{C}$ linkages between the aromatic rings.

\section{Conclusions}

The present paper has described a structural investigation of the dark pigment derived from black oat hull. By means of UV-Vis spectroscopy and EPR spectroscopy, the pigment was identified as melanin, while MALDI-TOF MS and FT-IR spectroscopy proved that oat melanin is a homopolymer built up from $p$-coumaric acid. The in vitro preparation of melanin from $p$-coumaric acid by the action of horseradish peroxidase was attempted for comparison. 
The results indicated that both polymers consist of oligomers of 4 to 9 monomer units. However the building blocks are connected to each other via $\mathrm{C}-\mathrm{C}$ linkages in oat melanin, in contrast with C-O-C linkages in the polymer prepared in vitro. The orientation of $p$-coumaric acid by the cell wall polymers may be presumed to contribute to the development of the C-C coupling of the aromatic rings in oat melanin.

\section{Experimental}

\subsection{Chemicals}

All solvents were HPLC grade and purchased from Molar Chemicals (Hungary). Horseradish peroxidase (donor-H,O, oxidoreductase, EC 1.11.1.7, type ZZ 230 units/mg) was obtained as lyophilized powder from Sigma (Hungary). $p$-Coumaric acid and 2,5-Dihydroxybenzoic acid (DHB) was obtained from Sigma.

\subsection{Plant material}

The Hungarian black oat variety GK Kormoran was grown in an experimental field in Kiszombor, Hungary in 2013. After harvesting the grains were stored at $4{ }^{\circ} \mathrm{C}$ in the dark. The grains were dehulled manually and the hull was milled to $0.5 \mathrm{~mm}$ particle size in a Retsch Mixer Mill MM 400.

\subsection{Isolation and purification of the oat melanin}

The melanin was isolated from oat hull and purified as described by Sava et al. (2001b) with some modifications. The grounded oat hull $(0.5 \mathrm{~g})$ was suspended in $0.5 \mathrm{M} \mathrm{NaOH}(6 \mathrm{ml})$ in a screw-capped glass tube. The sample was heated in a MBT $250 \mathrm{ETG}$ thermostat at $100{ }^{\circ} \mathrm{C}$ for $1 \mathrm{~h}$ with vortexing in every $15 \mathrm{~min}$. After subsequent centrifugation at 10,000 rpm for $10 \mathrm{~min}$, the supernatant was filtered through a GF/B glass microfiber filter and acidified with $7 \mathrm{M} \mathrm{HCl}$ to $\mathrm{pH}$ 2.5. To obtain the crude melanin, the mixture was stored at room temperature for $12 \mathrm{~h}$. After centrifugation at $10,000 \mathrm{rpm}$ for $10 \mathrm{~min}, 7 \mathrm{M} \mathrm{HCl}(3 \mathrm{ml})$ was added to the residue and the suspension was hydrolyzed at $100{ }^{\circ} \mathrm{C}$ for $2 \mathrm{~h}$. The resulting suspension was centrifuged at $10,000 \mathrm{rpm}$ for $10 \mathrm{~min}$ and the residue was washed with water until the supernant was neutral. The brown-black solid material was washed in turn with chloroform, ethyl acetate and ethanol and then dried. After dissolution in $1 \mathrm{M} \mathrm{NH}_{4} \mathrm{OH}$ the solution was filtered and acidified with 1 M HC1. The precipitate was filtered off and washed with water. This dissolution and precipitation cycle was repeated three times (Sava et al., 2001b).

\subsection{Enzymatic polymerization of $p$-coumaric acid}

$p$-Coumaric acid was subjected to horseradish peroxidase-catalyzed polymerization at room temperature under air in a mixture of $10 \mathrm{ml}$ of acetone and $15 \mathrm{ml}$ of $0.1 \mathrm{M}$ acetate buffer $(\mathrm{pH}$ 5), containing $2.5 \mathrm{mmol}$ of $p$-coumaric acid and $10 \mathrm{mg}$ of horseradish peroxidase. A stoichiometric amount of hydrogen peroxide (30\% aqueous solution) was added to the mixture dropwise at 15 -min intervals under vigorous stirring. The polymerization reaction was performed for $48 \mathrm{~h}$. After removal of the solvent with a rotary evaporator, the polymer that had formed was washed repeatedly (4-5 times) with water.

\subsection{UV-Vis absorption spectroscopy}

Ultraviolet-Vis absorption spectra of the sample solutions $(0.1 \mathrm{M}$ phosphate buffer, $\mathrm{pH}=8.0)$ were recorded on a Hewlett Packard 8452A diode array spectrophotometer in the interval 200-800 nm.

\subsection{EPR spectroscopy}


The EPR spectrum was obtained using a BRUKER EleXsys E500 spectrometer (microwave frequency $\sim 9.7 \mathrm{GHz}$, microwave power $1 \mathrm{~mW}$, modulation amplitude $1 \mathrm{G}$, modulation frequency $100 \mathrm{kHz}$ ). The EPR spectrum was simulated with the "EPR" computer program (Rockenbauer and Korecz, 1996).

\subsection{MALDI-TOF mass spectrometry}

Oat melanin isolated from GK Kormoran was suspended in 0,1\% trifluoroacetic acid. Melanin prepared in vitro using HRP was dissolved in $2 \%$ aqueous ammonia. An aliquot of the samples was spotted onto the MALDI target plate and let dry before adding the matrix (20 $\mathrm{mg} / \mathrm{ml}$ DHB in water). Mass spectra were recorded using a REFLEX III MALDI-TOF mass spectrometer (Bruker, Bremen, Germany) in the positive linear mode collecting 50-100 shots for each sample ( $\mathrm{m} / \mathrm{z}$ range: 100-2000). External calibration was performed using peptide standards.

\subsection{FT-IR spectroscopy}

A Bio-Rad Digilab Division FTS65A/896 FT-IR Spectrometer with a Harrick's Meridian ${ }^{\mathrm{TM}}$ SplitPea Single Reflection Diamond ATR Accessory was used to record the spectra. The measurements were performed in the range of $4000-400 \mathrm{~cm}^{-1}$ at $4 \mathrm{~cm}^{-1}$ optical resolution and 256 scans were taken to achieve good signal to noise ratio.

\section{Acknowledgements}

This research has been supported by the National Research, Development and Innovation Office of Hungary (No. PD 109760). We thank the EPR measurement possibilities to the Department of Physics, Budapest University of Technology and Economics. Special appreciation is extended to Prof. Dr. Árpád Molnár for critical reading of the manuscript.

\section{References}

Aktas, N., Sahiner, N., Kantoglu, O., Salih, B., Tanyolac, A., 2003. Biosynthesis and characterization of laccase catalyzed poly (catechol). J. Polym. Environ. 11, $123 \mathrm{e} 128$.

Atherton, N.M., Hendry, G.A.F., M€obius, K., Rohrer, M., T€orring, J.T., 1993. A free radical ubiquitously associated with senescence in plants: evidence for a quinone. Free Rad. Res. Comms. 19, $297 \mathrm{e} 301$.

Balasundram, N., Sundram, K., Samman, S., 2006. Phenolic compounds in plants and agri-industrial byproducts: antioxidant activity, occurrence, and potential uses. Food Chem. 99, 191e203.

Banerjee, A., Supakar, S., Banerjee, R., 2014. Melanin from the nitrogen-fixing bacterium azotobacter chroococcum: a spectroscopic characterization. PloS One 6, 25494.

Bartolom e, B., Bengoechea, M.L., G alvez, M.C., P erez-Ilzarbe, F.J., Estrella, I., Hern andez, T., G omez-Cordov es, C., 1993. Photodiode-array detection for elucidation of the structure of phenolic-compounds. J. Chromatogr. A 665, $119 \mathrm{e} 125$.

Bell, A.A., 1981. Biochemical mechanisms of disease resistance. Annu. Rev. Plant Physiol. 32, $21 \mathrm{e} 81$.

Bell, A.A.,Wheeler, M.H., 1986. Biosynthesis and functions of fungal melanins. Annu. Rev. Phytopathol. 24, 411e451.

Bunzel, M., 2010. Chemistry and occurrence of hydroxycinnamate oligomers. Phytochem. Rev. 9, 47e64. 
Bunzel, M., Heuermann, B., Kim, H., Ralph, J., 2008. Peroxidase catalyzed oligomerization of ferulic acid esters. J. Agric. Food Chem. 56, 10368e10375.

Chen, F.S., Mactaggart, J.M., Elofson, R.M., 1982. Chemical constituents in wild oat (Avena fatua) hulls and their effects on seed germination. Can. J. Plant Sci. 62, 155.

Claussen, K.A., Pepper, E.H., 1968. An examination of the brown pigments from barley leaves. Cereal Chem. 45, 124e132.

Coffman, F.A., 1961. Origin and history. In: Coffman, F.A. (Ed.), Oats and Oat

M. Varga et al. / Phytochemistry 130 (2016) 313e320 319

Improvement.

Colthup, N.B., Daly, L.H., Wiberley, S.E., 1990. Introduction to Infrared and Raman

Spectroscopy, third ed. Academic Press.

Crippa, P.R., Cristofoletti, V., Romeo, N., 1978. A band model for melanin deducted from optical absorption and photoconductivity experiments. Biochim. Biophys.

Acta 538, 164e170.

Dahlgard, M., Brewster, R.Q., 1958. Absorption spectra of some highly substituted diaryl ethers. J. Am. Chem. Soc. 80, 5861e5863.

Dec, J., Haider, K., Bollag, J.M., 2003. Release of substituents from phenolic compounds during oxidative coupling reactions. Chemosphere 52 (3), 549e556.

El Aghaa, A., Makrisb, D.P., 2012. Biocatalytic characteristics, product formation and putative pathway of $\mathrm{p}$-coumaric acid oxidation by a crude peroxidase from onion. Acta Aliment. 41, 304e315.

El-Obeid, A., Al-Harbi, S., Al-Jomah, N., Hassib, A., 2006. Herbal melanin modulates tumor necrosis factor alpha (TNF-alpha), interleukin 6 (IL-6) and vascular endothelial growth factor (VEGF) production. Phytomed 13 (5), 324e333.

Grotewold, E., 2006. The genetics and biochemistry of floral pigments. Annu. Rev.

Plant Biol. 57, 761e780.

Hollmann, F., Arends, I.W.C.E., 2012. Enzyme initiated radical polymerizations.

Polymers 4, 759e793.

Hsieh, P.-H., Lien, T.-F., 2012. Study of the physico-chemical properties and antioxidant activity of extracted melanins. J. Agric. Sci. 4, 217e229.

Ikeda, R., Sugihara, J., Uyama, H., Kobayashi, S., 1998. Enzymatic oxidative polymerization of 4-hydroxybenzoic acid derivatives to poly(phenylene oxide)s.

Polym. Int. 47, 295e301.

Ito, S., Fujita, K., 1985. Microanalysis of eumelanin and pheomelanin in hair and melanomas by chemical degradation and liquid chromatography. Anal. Biochem. $144,527 \mathrm{e} 536$.

Knochenmuss, R., Lehmann, E., Zenobi, R., 1998. Polymer cationization in matrixassisted laser desorption/ionization. Eur. Mass Spectrom. 4, 421e426.

Li, J.L., Sulaiman, M., Beckett, R.P., Minibayeva, F.V., 2010. Cell wall peroxidases in the liverwort Dumortiera hirsuta are responsible for extracellular superoxide production, and can display tyrosinase activity. Physiol. Plant 138 (4), 474e484.

Liu, H.-L., Huang, X.-F., Wan, X., Kong, L.-Y., 2007. Biotransformation of p-coumaric acid (1/4(2E)-3-(4-hydroxyphenyl)prop-2-enoic acid) by momordica charantia peroxidase. HCA 90, 1117e1132.

Marjasvaara, A., Torvinen, M., Kinnunen, H., Vainiotalo, P., 2006. Laccase-catalyzed polymerization of two phenolic compounds studied by matrix-assisted laser desorption/ionization time-of-flight and electrospray ionization fourier transform ion cyclotron resonance mass spectrometry with collision-induced dissociation experiments. Biomacromolecules 7, 1604e1609. 
Marshall, M.R., Kim, J., Wei, C., 2000. Enzymatic Browning in Fruits, Vegetables and Seafoods. FAO.

Mason, H.S., Ingram, D.J.E., Allen, B., 1960. The Free radical property of melanins. Arch. Biochem. Biophys. 86, 225e230.

Mohan, J., 2002. Organic Spectroscopy: Principles and Applications, second ed. Alpha Science International.

Morison, W.L., 1985. What is the function of melanin? Arch. Dermatol. 121, $1160 \mathrm{e} 1163$.

Napolitano, A., Pezzella, A., Prota, G., Seraglia, R., Traldi, P., 1996a. A reassessment of the structure of 5, 6-dihydroxyindole-2-carboxylic acid melanins by matrixassisted laser desorption/ionization mass spectrometry. Rapid Commun. Mass Spectrom. 10, 204e208.

Napolitano, A., Pezzella, A., Prota, G., Seraglia, R., Traldi, P., 1996b. Structural analysis of synthetic melanins from 5, 6-dihydroxyindole by matrix-assisted laser desorption/ionization mass spectrometry. Rapid Commun. Mass Spectrom. 10, $468 \mathrm{e} 472$.

Napolitano, A., Vincensi, M.R., Di Donato, P., Monfrecola, G., Prota, G., 2000.

Microanalysis of melanins in mammalian hair by alkaline hydrogen peroxide degradation: identification of a new structural marker of pheomelanins.

J. Invest. Dermatol. 114, 1141e1147.

Nicolaus, R.A., 1968. Melanins. Hermann, Paris.

Nielen, M.W.F., 1999. Maldi time-of-flight mass spectrometry of synthetic polymers. Mass Spectrom. Rev. 18, 309e344.

Ortonne, J.-P., 2002. Photoprotective properties of skin melanin. Br. J. Dermatol. 146, $7 \mathrm{e} 10$.

Pezzella, A., Napolitano, A., d'Ischia, M., Prota, G., Seraglia, R., Traldi, P., 1997. Identification of partially degraded oligomers of 5, 6-dihydroxyindole-2-carboxylic acid in sepia melanin by matrix-assisted laser desorption/ionization mass spectrometry. Rapid Commun. Mass Spectrom. 11, 368e 372. Pradedova, E.V., Nimaeva, O.D., Trukhan, I.S., Salyaev, R.K., 2013. Tyrosinase activity of peroxidase of red beet root vacuoles and plastids. Dokl. Biochem. Biophys. $448,9 \mathrm{e} 12$.

Ralph, J., Bunzel, M., Marita, J.M., Hatfield, R.D., Lu, F., Kim, H., Schatz, P.F., Grabber, J.H., Steinhart, H., 2004. Peroxidase-dependent cross-linking reactions of p-hydroxycinnamates in plant cell walls. Phytochem. Rev. 3, 79e96.

Rasper, V.F., 1979. Chemical and physical characteristics of dietary cereal fiber. In: Inglett, G.E., Falkehag, S.I. (Eds.), Dietary Fiber: Chemistry and Nutrition. Academic Press, New York, pp. 93e115.

Rockenbauer, A., Korecz, L., 1996. Automatic computer simulations of ESR spectra. Appl. Magn. Reson. 10, 29e43.

Sava, V.M., Galkin, B.N., Hong, M.-Y., Yang, P.-C., Huang, G.S., 2001a. A novel melanin-like pigment derived from black tea leaves with immuno-stimulating activity. Food Res. Int. 34, 337e343.

Sava, V.M., Yang, S.M., Hong, M.Y., Yang, P.C., Huang, G.S., 2001b. Isolation and characterization of melanic pigments derived from tea and tea polyphenols.

Food Chem. 73, 177e184.

Socrates, G., 2004. Infrared and Raman Characteristic Group Frequencies: Tables and Charts, third ed. Wiley.

Solano, F., 2014. Melanins: skin pigments and much moredtypes, structural models, biological functions, and formation routes. New J. Sci. 28. Article ID 
498276.

Tanaka, Y., Sasaki, N., Ohmiya, A., 2008. Biosynthesis of plant pigments: anthocyanins, betalains and carotenoids. Plant J. 54 (4), 733e749.

Tran, M.L., Powell, B.J., Meredith, P., 2006. Chemical and structural disorder in eumelanins: a possible explanation for broadband absorbance. Biophys. J. 90

(3), $743 \mathrm{e} 752$.

Vars anyi, G., 1973. Assignments for Vibrational Spectra of 700 Benzene Derivatives. Akademiai Kiado, Budapest.

Wang, H., Pan, Y., Tang, X., Huang, Z., 2006. Isolation and characterization of melanin from Osmanthus fragrans' seeds. LWT 39, 496e502.

Welch, R.W., Hayward, M.V., Jones, D.I.H., 1983. The composition of oat husk and its variation due to genetic and other factors. J. Sci. Food Agric. 34, 417e426.

$\mathrm{Xu}, \mathrm{F} . \mathrm{F} ., 1996$. Oxidation of phenols, anilines, and benzenethiols by fungal laccases:

correlation between activity and redox potentials as well as halide inhibition.

Biochemistry 35 (23), $7608 \mathrm{e} 7614$.

Xu, P., Uyama, H., Whitten, J.E., Kobayasi, S., Kaplan, D.L., 2005. Peroxidase-catalyzed in situ polymerization of surface orientated caffeic acid. J. Am. Chem. Soc. 127, $11745 \mathrm{e} 11753$.

Zhang, J., Zenobi, R., 2004. Matrix-dependent cationization in MALDI mass spectrometry. J. Mass Spectrom. 39, 808e816. 


\section{Figure Captions}

Fig. 1. UV spectrum of the black pigment obtained from the oat hull.

Fig. 2. EPR spectrum of the black pigment obtained from the oat hull.

Fig. 3. MALDI-TOF mass spectrum of the black pigment obtained from the oat hull.

Fig. 4. Chemical structures and molecular masses of the major phenolic monomers identified in plants.

Fig. 5. FT-IR spectra of $p$-coumaric acid (a) and oat melanin (b).

Fig. 6. The possible resonance structures of the radical obtained from $p$-coumaric acid.

Fig. 7. The proposed structure of oat melanin.

Fig. 8. UV spectra of $p$-coumaric acid (a) and the in vitro synthetized polymer (b).

Fig. 9. MALDI-TOF mass spectrum of the in vitro synthetized polymer.

Fig. 10. FT-IR spectra of the in vitro synthetized polymer.

Fig. 11. The proposed structure of the in vitro synthetized polymer. 


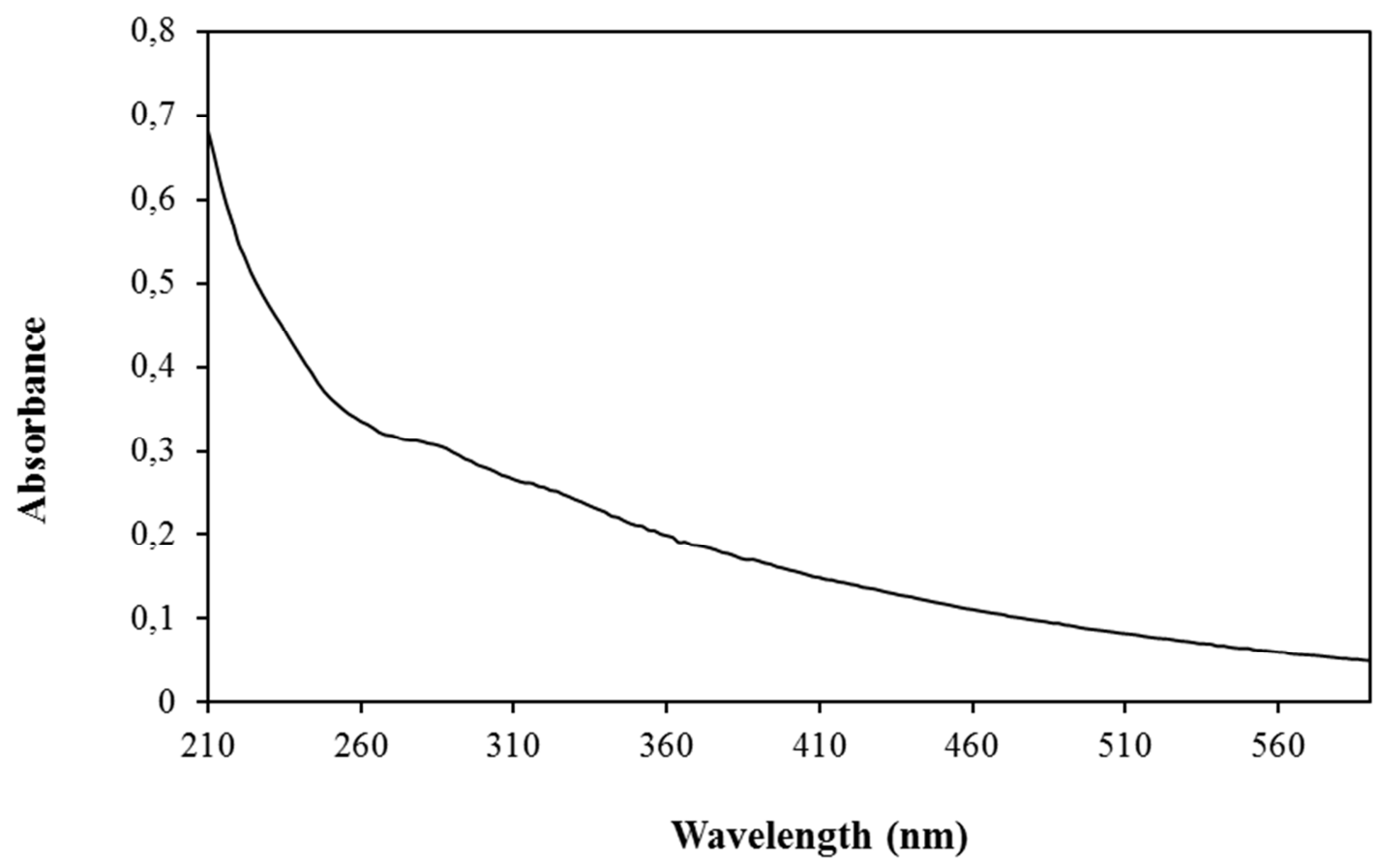

Fig. 1. UV spectrum of the black pigment obtained from the oat hull. 


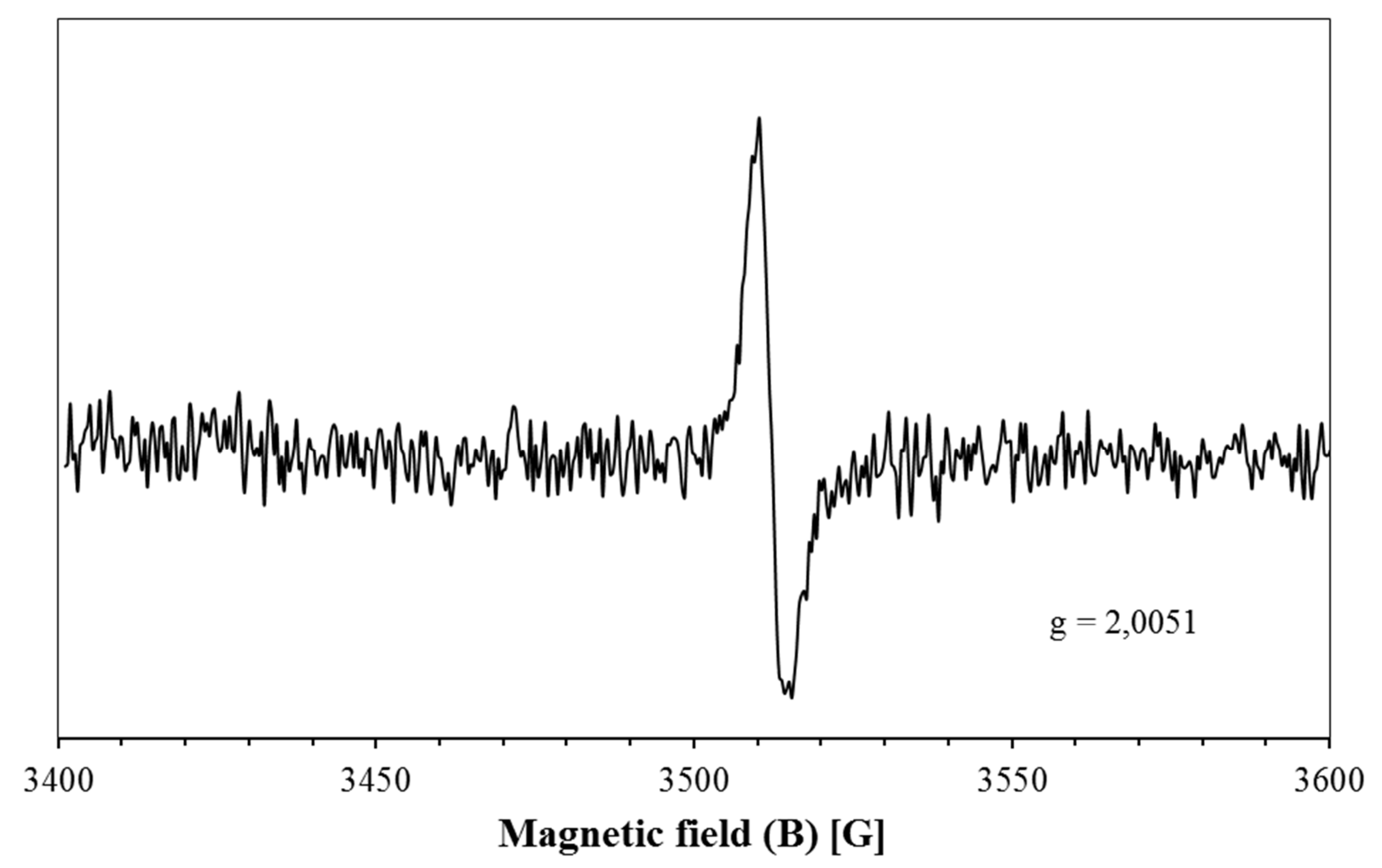

Fig. 2. EPR spectrum of the black pigment obtained from the oat hull. 


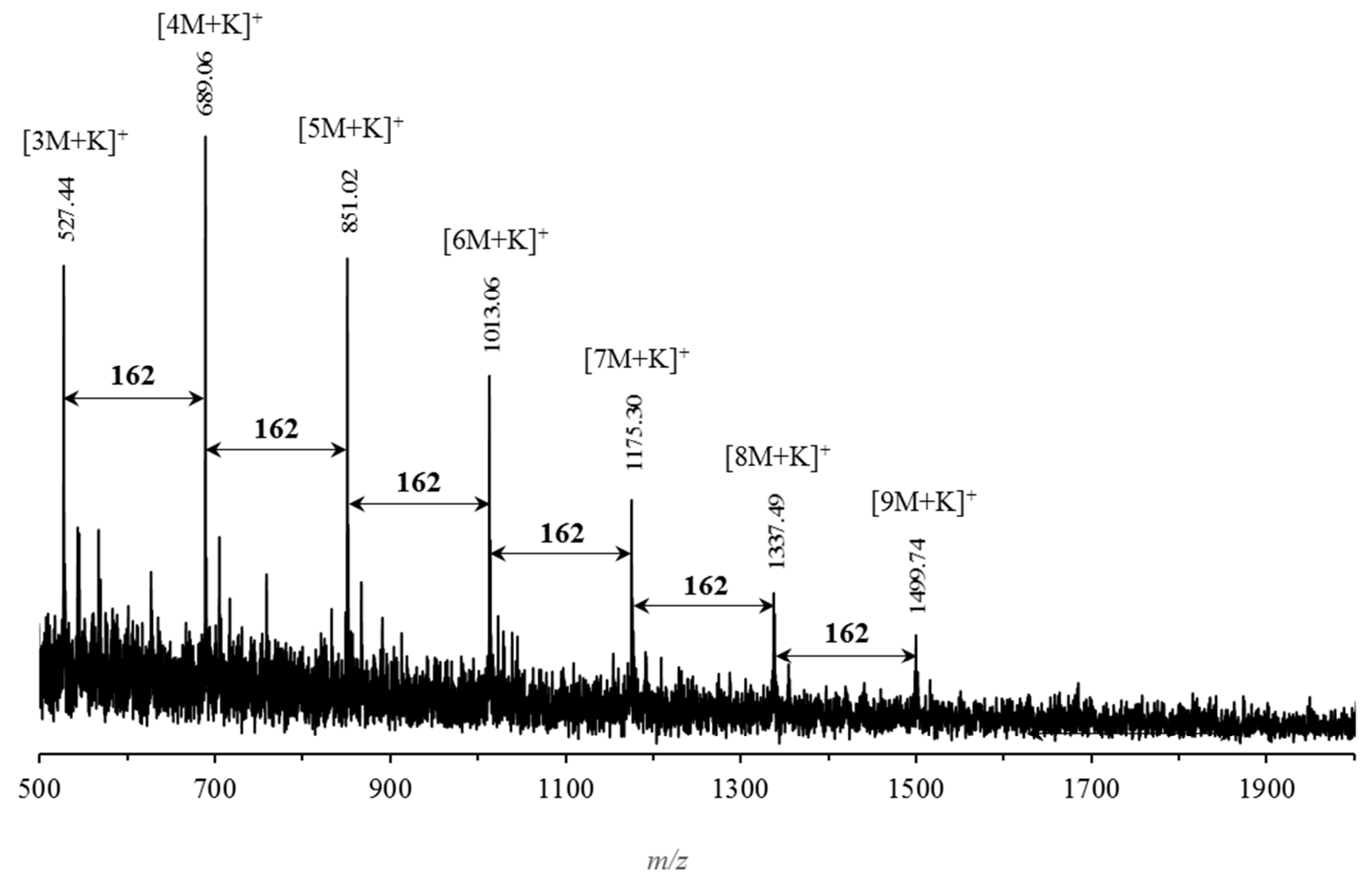

Fig. 3. MALDI-TOF mass spectrum of the black pigment obtained from the oat hull. 
<smiles>[R]c1cc(C(=O)O)cc([R])c1O</smiles>

\begin{tabular}{llll}
\hline Compound & $\mathrm{R}_{1}$ & $\mathrm{R}_{2}$ & $\mathrm{M}_{\mathrm{r}}$ \\
\hline$p$-OH-benzoic acid & $\mathrm{H}$ & $\mathrm{H}$ & 138.12 \\
protocatechuic acid & $\mathrm{OH}$ & $\mathrm{H}$ & 154.12 \\
gallic acid & $\mathrm{OH}$ & $\mathrm{OH}$ & 170.12 \\
vanillic acid & $\mathrm{OCH}_{3}$ & $\mathrm{H}$ & 168.14 \\
syringic acid & $\mathrm{OCH}_{3}$ & $\mathrm{OCH}_{3}$ & 198.17 \\
\hline
\end{tabular}<smiles>[R]c1cc(/C=C/C(=O)O)cc([R])c1O</smiles>

\begin{tabular}{llll}
\hline Compound & $\mathrm{R}_{1}$ & $\mathrm{R}_{2}$ & $\mathrm{M}_{\mathrm{r}}$ \\
\hline$p$-coumaric acid & $\mathrm{H}$ & $\mathrm{H}$ & 164.16 \\
caffeic acid & $\mathrm{OH}$ & $\mathrm{H}$ & 180.16 \\
ferulic acid & $\mathrm{OCH}_{3}$ & $\mathrm{OH}$ & 194.18 \\
sinapic acid & $\mathrm{OCH}_{3}$ & $\mathrm{OCH}_{3}$ & 224.21 \\
\hline
\end{tabular}

Fig. 4. Chemical structures and molecular masses of the major phenolic monomers identified in plants. 


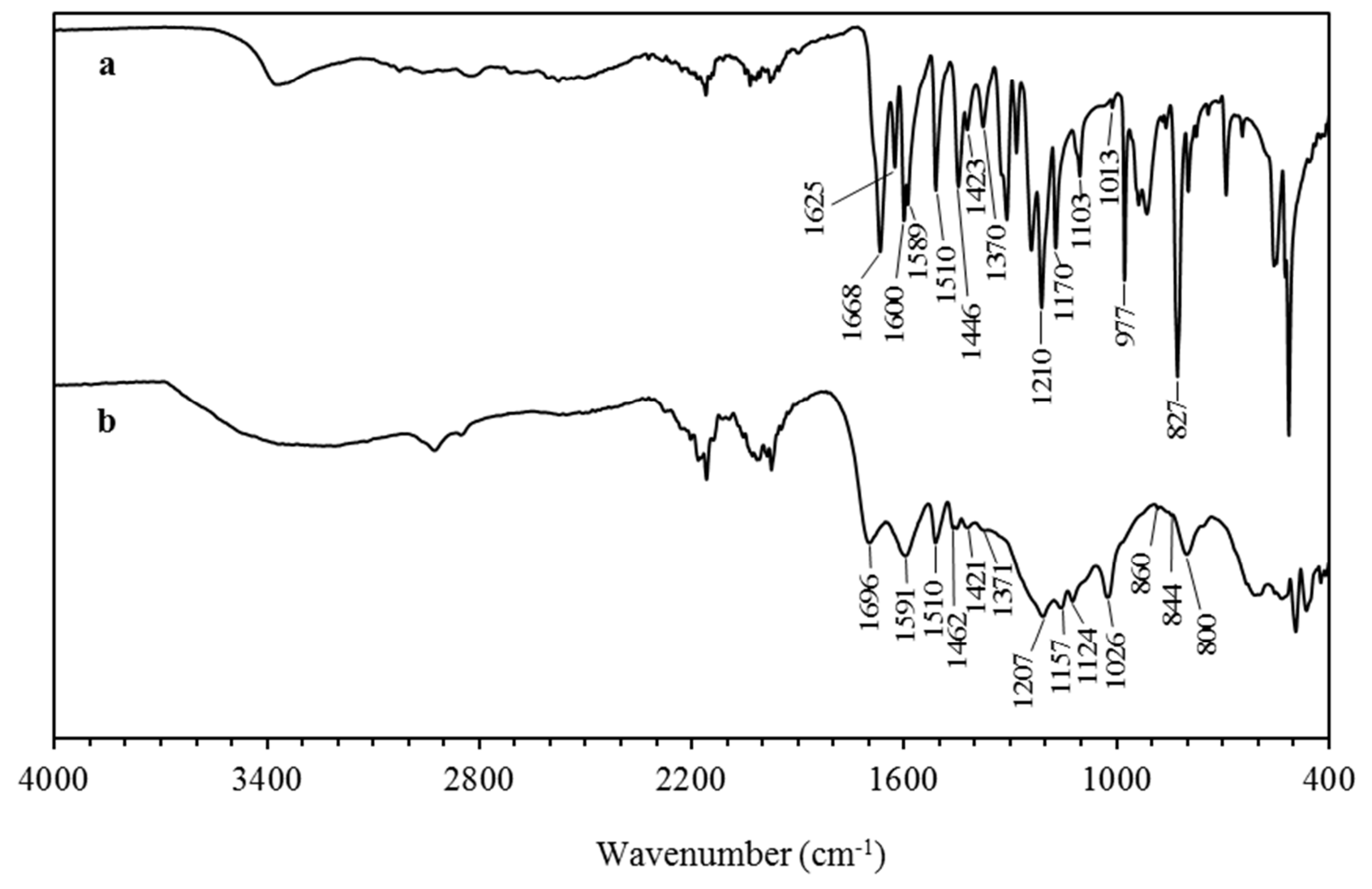

Fig. 5. FT-IR spectra of $p$-coumaric acid (a) and oat melanin (b). 


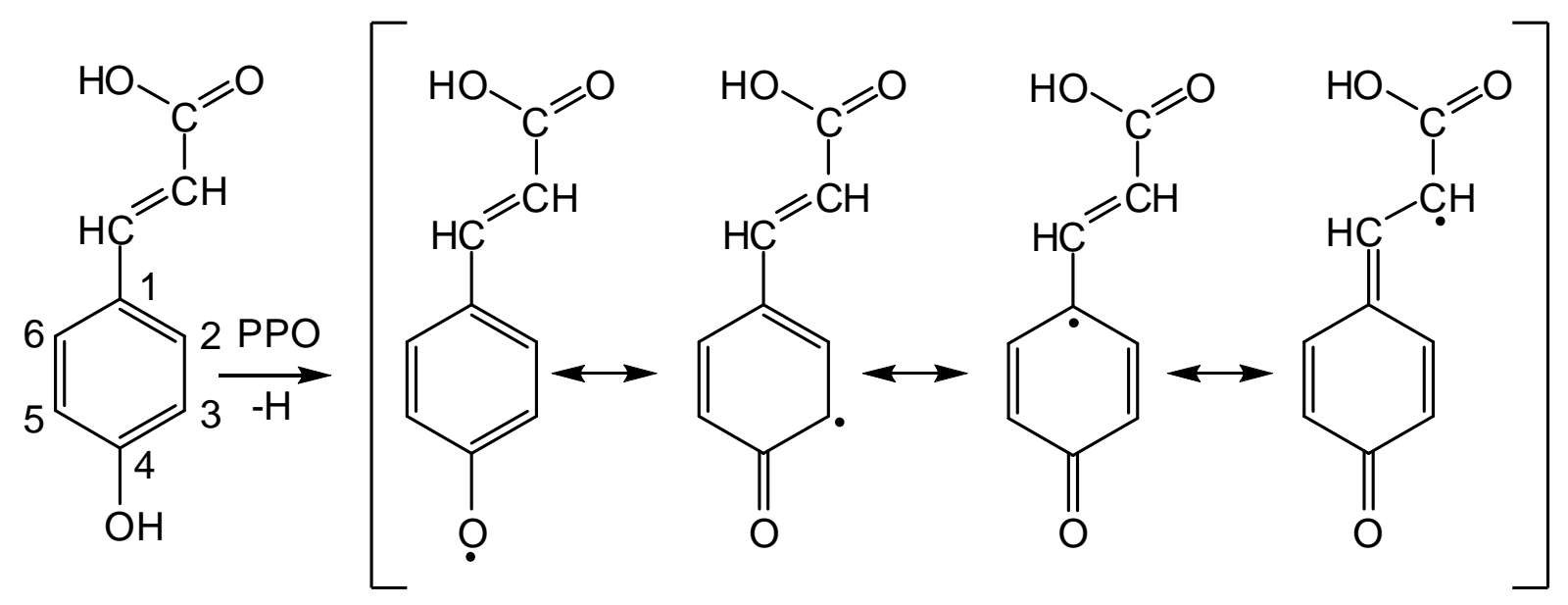

Fig. 6. The possible resonance structures of the radical obtained from $p$-coumaric acid. 


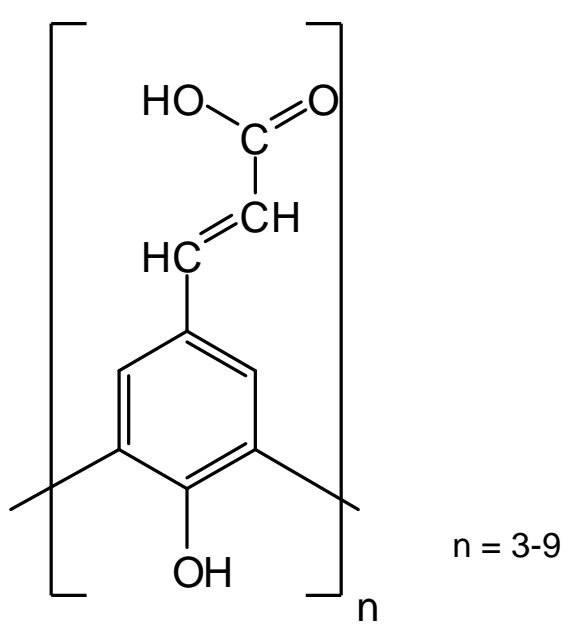

Fig. 7. The proposed structure of oat melanin. 


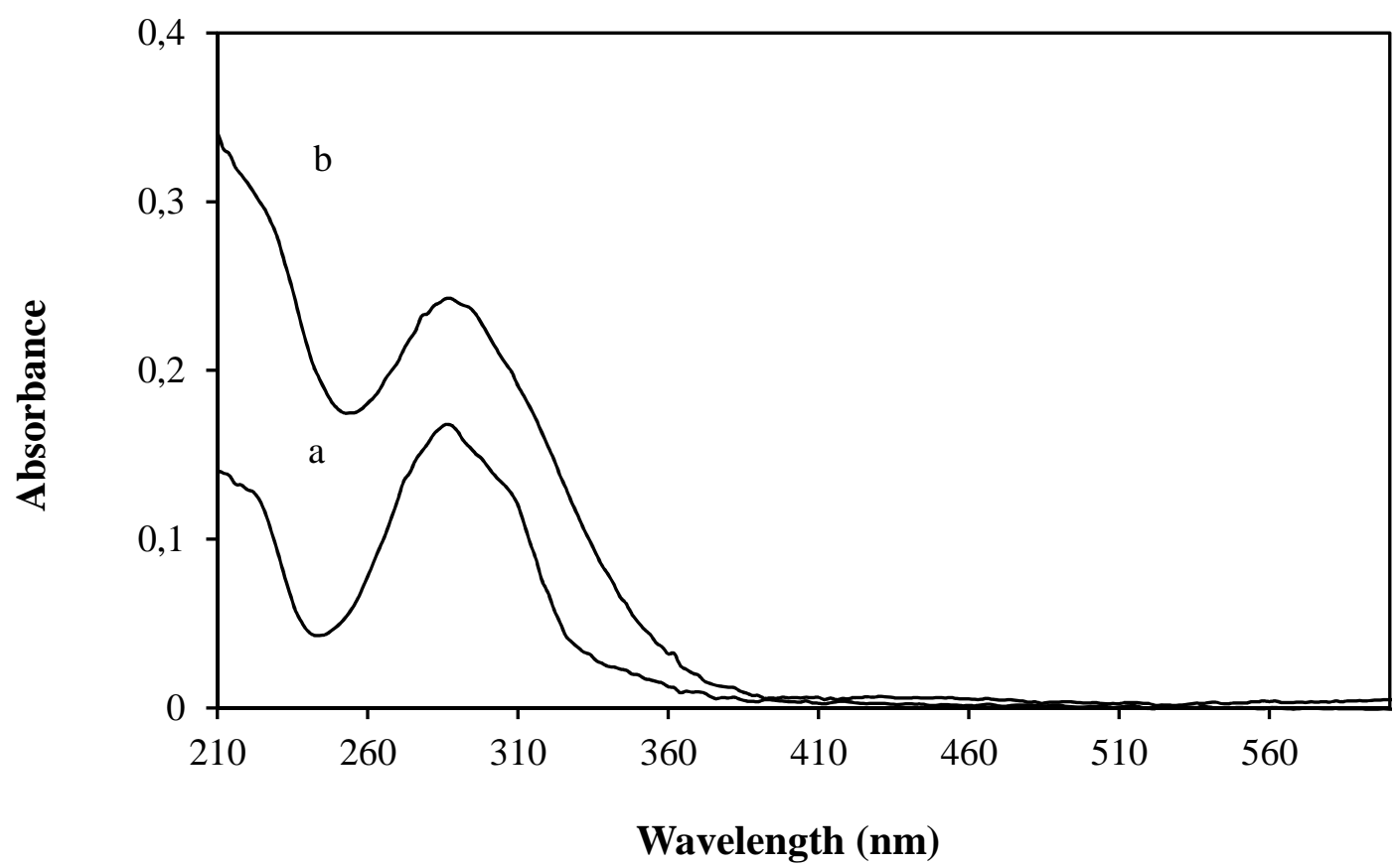

Fig. 8. UV spectra of $p$-coumaric acid (a) and the in vitro synthetized polymer (b). 

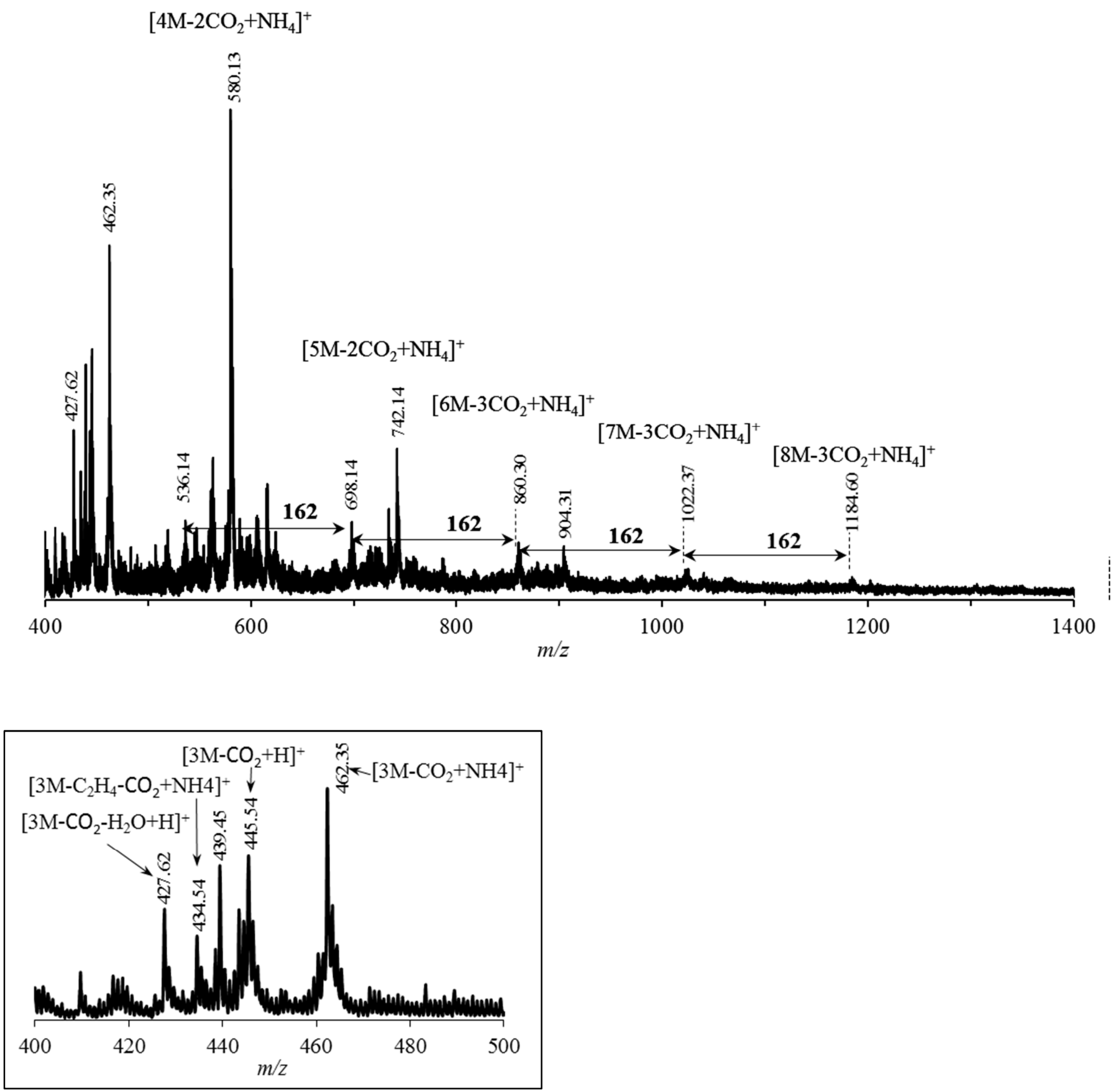

Fig. 9. MALDI-TOF mass spectrum of the in vitro synthetized polymer. 


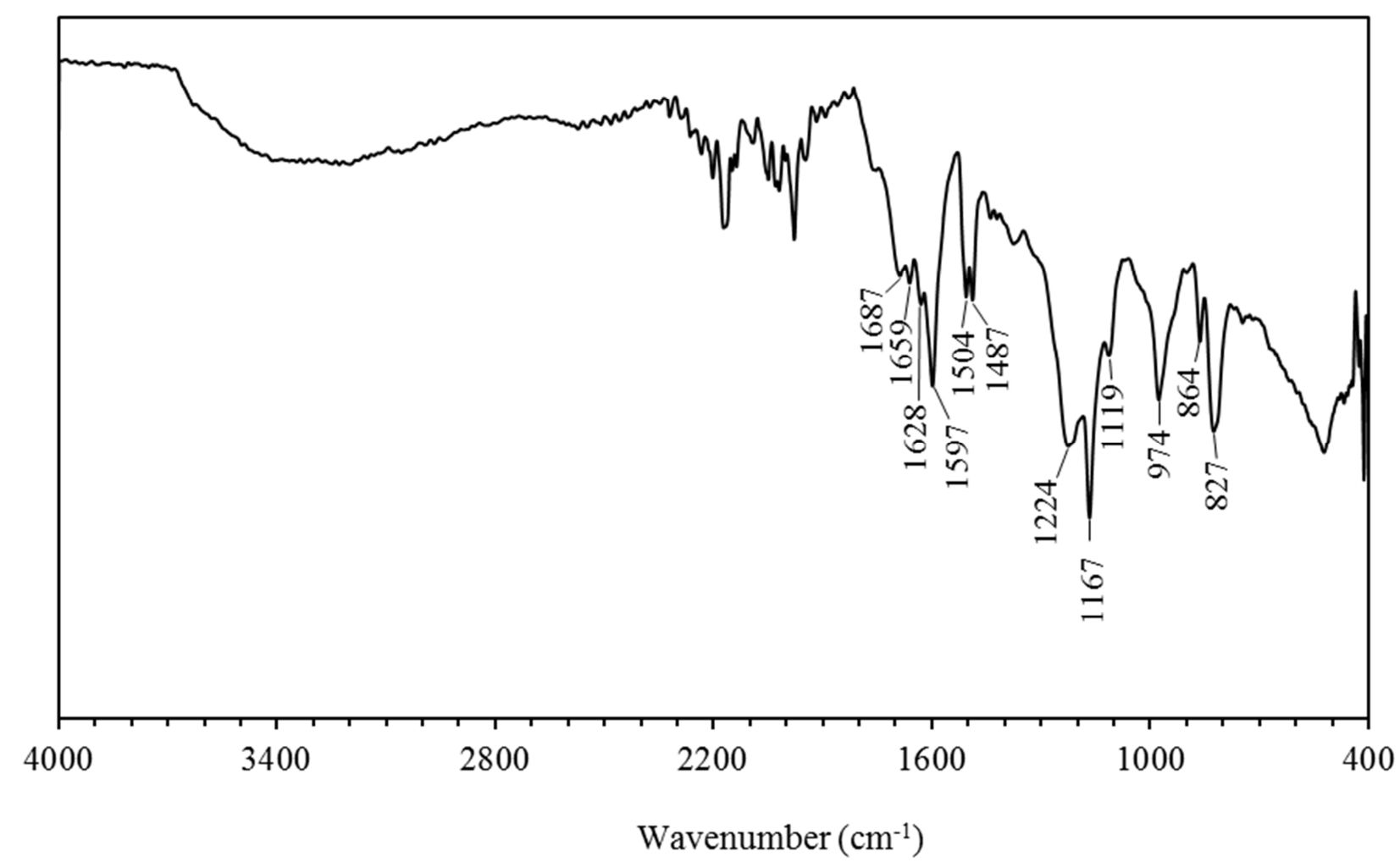

Fig. 10. FT-IR spectra of the in vitro synthetized polymer. 


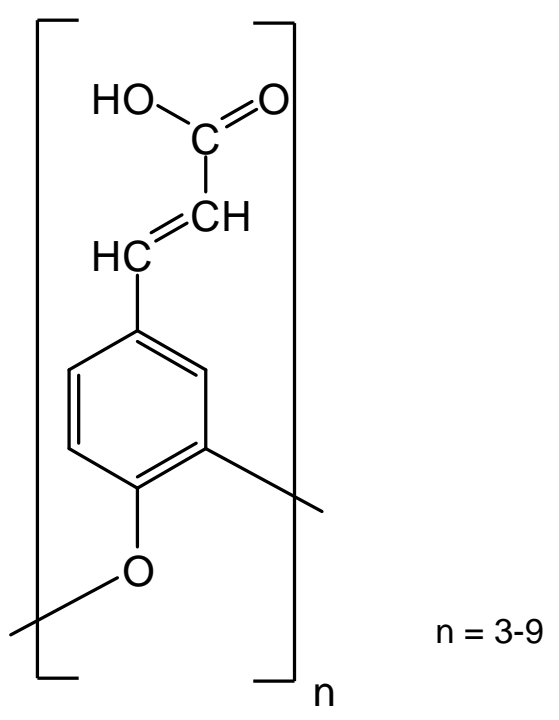

Fig. 11. The proposed structure of the in vitro synthetized polymer. 